\title{
Fire Resistant K-Based Metakaolin Geopolymer for Passive Fire Protection of Concrete Tunnel Linings
}

\author{
Konstantinos Sakkas',2, Stergiani Kapelari'1, Dimitrios Panias', Pavlos Nomikos², \\ Alexandros Sofianos ${ }^{2}$ \\ ${ }^{1}$ Laboratory of Metallurgy, School of Mining and Metallurgical Engineering, National Technical University of \\ Athens, Athens, Greece \\ ${ }^{2}$ Laboratory of Tunnelling, School of Mining and Metallurgical Engineering, National Technical University of \\ Athens, Athens, Greece \\ Email: sakkas@metal.ntua.gr
}

Received 27 June 2014; revised 31 July 2014; accepted 7 September 2014

Copyright (C) 2014 by authors and OALib.

This work is licensed under the Creative Commons Attribution International License (CC BY). http://creativecommons.org/licenses/by/4.0/

(c) (i) Open Access

\begin{abstract}
A fire resistant metakaolin geopolymer is developed and its performance under thermal loading is examined in this paper. The geopolymer was prepared by mixing metakaolin, doped with solid $\mathrm{SiO}_{2}$, with a highly alkaline potassium hydroxide aqueous phase in order to create a paste that was subsequently cured at $70^{\circ} \mathrm{C}$ for a certain period of time. The addition of solid $\mathrm{SiO}_{2}$ was important in order the geopolymer developed to be fire resistant for temperatures up to $1350^{\circ} \mathrm{C}$. The mechanical, physical and thermal properties of the metakaolin geopolymer were measured and compared with available commercial fire resistant materials. The behavior of the metakaolin geopolymer upon exposure on fire was studied following the EFNARC guidelines for testing of passive fire protection for concrete tunnels linings. The geopolymer was subjected to the most severe fire scenario, the Rijks Water Staat (RWS) temperature-time curve. During the test, the temperature in the geopolymer/concrete interface remained under $220^{\circ} \mathrm{C}$, which is $160^{\circ} \mathrm{C}$ lower than the RWS test requirement, proving the ability of material to work successfully as an efficient thermal barrier. After the test the surface of the geopolymer had exfoliated and cracked, without losing its structural integrity. Thus, the concrete slab protected by the geopolymer did not appear any form of spalling or degradation of its compressive strength.
\end{abstract}

\section{Keywords}

Metakaolin, Geopolymer, Tunnel Linings, Passive Fire Protection

Subject Areas: Composite Material, Inorganic Chemistry, Material Experiment

How to cite this paper: Sakkas, K., Kapelari, S., Panias, D., Nomikos, P. and Sofianos, A. (2014) Fire Resistant K-Based Metakaolin Geopolymer for Passive Fire Protection of Concrete Tunnel Linings. Open Access Library Journal, 1: e806. 


\section{Introduction}

Fires in tunnels are a major hazard to human life and they also cause costly damage to surrounding infrastructure due to explosive spalling of the concrete lining. Explosive spalling occurs when concrete is exposed to fire. It results in loss of section and reduction in the load bearing capacity. Although spalling occurs frequently in buildings, recent incidents in tunnel fires (Channel, Great Belt, Mont Blanc, Tauern), where whole concrete segments have been destroyed, have highlighted the problem in the public's mind.

In general, explosive spalling is more likely the higher the rate of heating, the stronger the concrete, the higher the moisture level and the larger the imposed compressive load. It occurs normally at temperatures higher than $300^{\circ} \mathrm{C}$ where in addition substantial reduction of concrete mechanical strengths takes place [1]. It is obvious that the solution of the spalling problem is a primary requirement in any new tunnel design. In addition to the damage caused by fire to concrete, special attention has to be paid to the damage caused to structural steel rebars that normally reinforce the concrete structures. Structural steelundergoes degradation in stiffness, yield capacity and ultimate capacity while undergoes substantial thermal expansion when exposed to elevated temperatures [1]. For this reason, structural steel is considered to have lost its strength at temperatures between $550^{\circ} \mathrm{C}$ and $600^{\circ} \mathrm{C}$ [2]. Therefore, steel and concrete are both fire sensitive construction elements requiring passive protection against fire in order to be capable of withstanding the effects of fire for an appropriate period without loss of stability.

The most utilized passive fire protection method is the cladding of the building structural elements by a fire resistant material, which creates a protective external insulation envelope. The materials commonly used for passive fire protection are several cement or gypsum based composites [1]. Fire resistant geopolymers have been developed since 1970 when J. Davidovits carried out research into new heat resistant materials as an aftermath of catastrophic fires in France [3]. Until today, many fire resistant geopolymers, composite geopolymers and geopolymer cements based on several raw materials (Fly ashes, Metakaolin, slags, etc.) have been developed and studied [4]-[6]. However, none of the metakaolin based geopolymers has been tested for its fire resistance according to specifications and guidelines for testing of passive fire protection for concrete tunnels lining by EFNARC.

This work aims at designing and evaluating the performance under thermal loading of a fire resistant K-based metakaolin geopolymer for external passive fire protection of concrete tunnels linings. Its efficiency under the most severe RWS (Rijswaterstaat) thermal loading is assessed by thermal exposure laboratory testing following the EFNARC guidelines [7]. Also the material's mechanical and physical properties will be measured.

\section{Experimental}

\subsection{Materials}

The metakaolin that was used in this study was provided from AGS Mineraux, a member of Imerys Minerals. Metakaolin had a mean particle size $\left(\mathrm{d}_{50}\right)$ of $13.68 \mu \mathrm{m}$ measured on a MALVERN Laser Particle Size Analyzer. As is shown in Table 1, it is a material rich in silica and alumina oxide. Its mineralogical analysis showed that it is mainly composed of an X-ray amorphous silicate or aluminosilicate phase which is accompanied by crystalline mineralogical phases that belong to Illite [(K, $\left.\mathrm{H}_{3} \mathrm{O}\right)(\mathrm{Al}, \mathrm{Mg}, \mathrm{Fe})_{2}(\mathrm{Si}, \mathrm{Al})_{4} \mathrm{O}_{10}\left[(\mathrm{OH})_{2},\left(\mathrm{H}_{2} \mathrm{O}\right)\right], \mathrm{Quartz}(\mathrm{SiO})$, Anatase $\left(\mathrm{TiO}_{2}\right)$ and Tridymite $\left(\mathrm{SiO}_{2}\right)$.

Also pure silicon dioxide (particle size $<64 \mu \mathrm{m}$ ) provided bySigma Aldrichwas used for the synthesis of metakaolin geopolymer. Finally, a alkaline potassium hydroxide solution was also used for the synthesis of inorganic polymers. The solution was prepared by dissolving pellets (Merck, 99.5\% purity) of anhydrous potassium hydroxide in deionized water.

Table 1. Chemical analysis of themetakaolin used.

\begin{tabular}{cc}
\hline Species & $\% \mathrm{w} / \mathrm{w}$ \\
\hline $\mathrm{SiO}_{2}$ & 52.66 \\
$\mathrm{Al}_{2} \mathrm{O}_{3}$ & 40.97 \\
$\mathrm{Fe}_{2} \mathrm{O}_{3}$ & 1.83 \\
$\mathrm{~K}_{2} \mathrm{O}$ & 1.18 \\
$\mathrm{TiO}_{2}$ & 1.43 \\
$\mathrm{Na}_{2} \mathrm{O}$ & 0.55 \\
\hline
\end{tabular}




\subsection{Design of a Fire Resistant Metakaolin Geopolymer}

Target of this work was the design of a metakaolin geopolymer which can resist to the requirements of a passive fire protection material according to National Fire Protection Association (NFPA 502). An effective passive fire protection material according to the NFPA 502 has to be incombustible, capable of withstanding at temperatures as high as $1350^{\circ} \mathrm{C}$ and performed as excellent heat barrier keeping the temperature at the concrete surface below $380^{\circ} \mathrm{C}$.

Taking into account that the main components of metakaolin are silica and alumina (Table 1), the fire performance of a K-based metakaolin geopolymer can be described by the ternary $\mathrm{SiO}_{2}-\mathrm{Al}_{2} \mathrm{O}_{3}-\mathrm{K}_{2} \mathrm{O}$ system shown in Figure 1. In this system four potassium aluminosilicate compounds are formed. The potash feldspar $\left(\mathrm{K}_{2} \mathrm{O} \cdot \mathrm{Al}_{2} \mathrm{O}_{3} \cdot 6 \mathrm{SiO}_{2}\right)$ that melts incongruently at $1150^{\circ} \mathrm{C}$ is the less refractory phase and therefore its stoichiometry is not taken into consideration for the development of a fire resistant geopolymer for protection of tunnel linings. Leucite $\left(\mathrm{K}_{2} \mathrm{O} \cdot \mathrm{Al}_{2} \mathrm{O}_{3} \cdot 4 \mathrm{SiO}_{2}\right)$ is a refractory compound with congruent melting temperature at $1693^{\circ} \mathrm{C}$. Its field occupies a large area at the center of $\mathrm{K}_{2} \mathrm{O}-\mathrm{SiO}_{2}-\mathrm{Al}_{2} \mathrm{O}_{3}$ system including a broad region of geopolymeric compositions with liquidus temperatures higher than $1350^{\circ} \mathrm{C}$. In addition, two other enriched in $\mathrm{K}_{2} \mathrm{O}$ and $\mathrm{Al}_{2} \mathrm{O}_{3}$ compounds, $\mathrm{K}_{2} \mathrm{O} \cdot \mathrm{Al}_{2} \mathrm{O}_{3} \cdot 2 \mathrm{SiO}_{2}$ and $\mathrm{K}_{2} \mathrm{O} \cdot \mathrm{Al}_{2} \mathrm{O}_{3} \cdot \mathrm{SiO}_{2}$, with congruent melting points well above $1700^{\circ} \mathrm{C}$ exist in the ternary $\mathrm{K}_{2} \mathrm{O}-\mathrm{SiO}_{2}-\mathrm{Al}_{2} \mathrm{O}_{3}$ system. Among the three refractory compounds, the Leucite stoichiometry is the most preferable one for a fire resistant metakaolin geopolymer with standing at temperatures as high as $1350^{\circ} \mathrm{C}$ as it minimizes the amount of caustic potash and alumina that has to be mixed with the metakaolin in forming a geopolymeric paste and thus minimizing the production cost.

\subsection{Synthesis-Experimental Procedure}

The fire resistant metakaolin geopolymer was prepared according to the following procedure. A homogeneous viscous paste with the composition shown in Table 2, was initially prepared by mixing mechanically themetakaolinand silicon dioxide with $13.33 \mathrm{M}$ potassium hydroxide solution. Then, the paste was molded in appropriate open plastic (Ertacetal) molds and was cured at $70^{\circ} \mathrm{C}$ for 48 hours. After curing, the specimens were demolded and the mechanical and thermophysical properties of the produced materials were measured.

\subsection{Analysis and Tests}

The geopolymer properties that were studied include uniaxial compressive strength, tensile strength, Young's modulus, thermal conductivity, apparent density, water absorption, porosity, shore hardness and behaviour upon exposure on fire. Compressive strength was measured according to ASTM C109 standard test using cubic specimens of $50 \mathrm{~mm}$ edge. The tensile strength was measured indirectly with the splitting tensile test (Brazilian test) performed on disc specimens of $55 \mathrm{~mm}$ diameter and $27.5 \mathrm{~mm}$ thickness, by adopting the relevant ISRM suggested method [8]. The Young's modulus of the material was measured under uniaxial compression of prismatic specimens of $50 \times 50 \mathrm{~mm}^{2}$ cross section and $100 \mathrm{~mm}$ height. The axial strain was monitored by binding foil strain gauges in the middle-height of the specimen. The cold water absorption was determined according to the EN 771-1: 2003 standard test. The thermal conductivity of the material was measured with the HFM 436 Lambda Heat Flow Meter according to ASTM C518 standard test using a specimen of $15 \times 15 \times 2 \mathrm{~cm}$. The apparent density was calculated by measuring the dimensions of the specimens with a precision electronic calliper as well as the weight of specimens with a precision balance. Open porosity was measured with Archimedes method. The hardness of the geopolymer was measured according to ASTMD2240-00 standard test with shore D method.

The study of the material behaviour upon exposure on fire was based on the EFNARC guidelines [7] for testing of passive fire protection for concrete tunnels linings. The laboratory tests were performed in a furnace which has the ability to simulate the standard RWS temperature-time curve (Figure 2) that describes the most severe fire incident that can happen in tunnels. For this test a $15 \times 15 \times 15 \mathrm{~cm}$ (thickness) composite specimen was prepared, consisting of $5 \mathrm{~cm}$ thick geopolymer material and $10 \mathrm{~cm}$ thick concrete slab (Figure 3(a)). The adhesion of the two materials was enhanced by the use of steel anchors. The test was performed 28 days after the production of the specimen. During the test (Figure 3(b)) the free surface of the geopolymer material is exposed to a heat flux simulating the RWS fire scenario. The developed temperature at the interface between the concrete and the geopolymermaterial was measured by using a "K"-type thermocouple, while the temperature of 


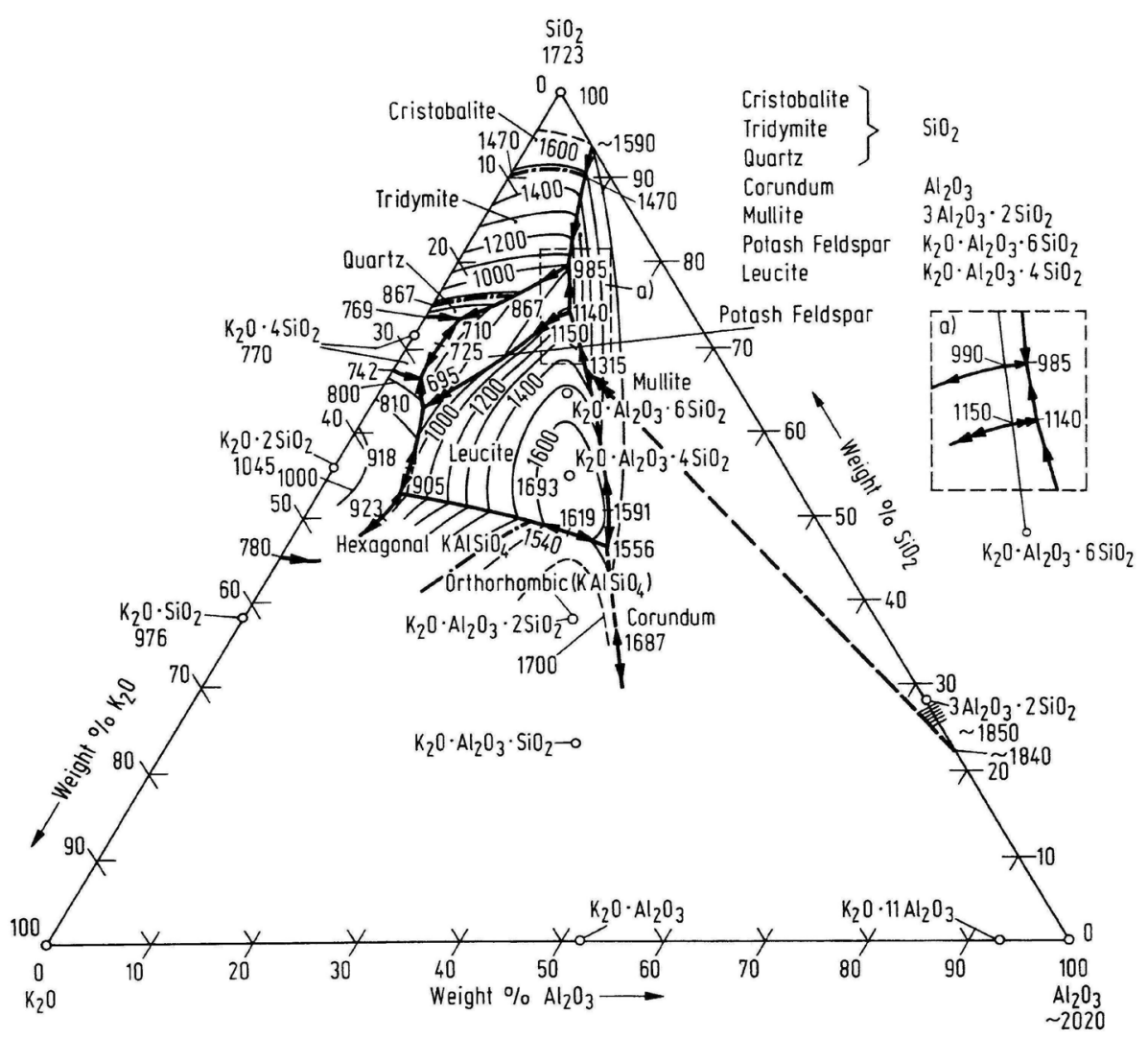

Figure 1. Liquidus surfaces in the ternary oxide systems $\mathrm{SiO}_{2}-\mathrm{K}_{2} \mathrm{O}-\mathrm{Al}_{2} \mathrm{O}_{3}[10]$.

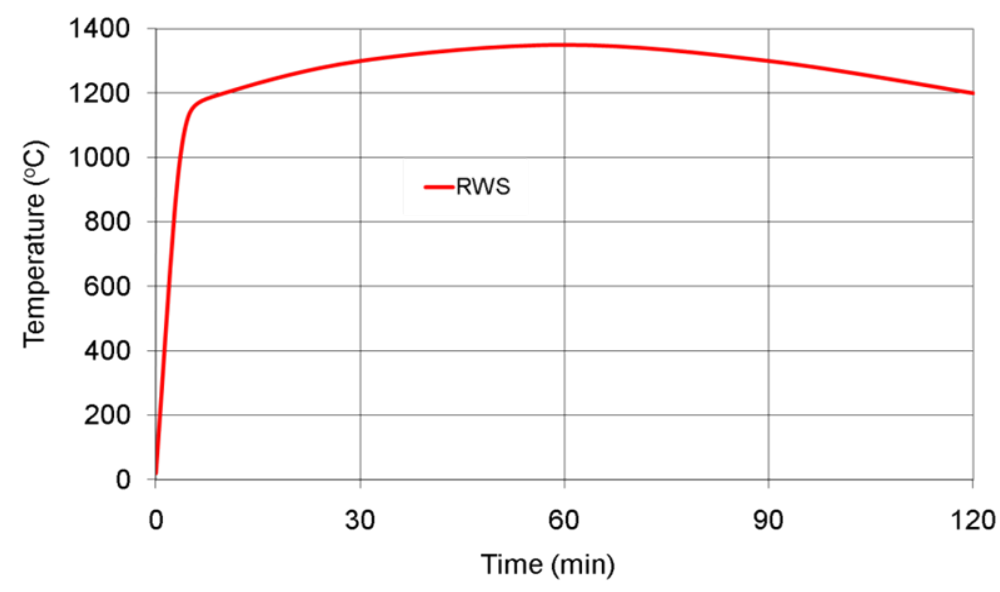

Figure 2. RWS curve.

Table 2. Synthesis and curing conditions of the geopolymermaterial.

\begin{tabular}{cc}
\hline Material & $\% \mathrm{w} / \mathrm{w}$ \\
\hline Metakaolin & 40.2 \\
$\mathrm{SiO}_{2}$ & 17.6 \\
$\mathrm{KOH}$ & 17.95 \\
$\mathrm{H}_{2} \mathrm{O}$ & 24.1 \\
Curing temperature $\left({ }^{\circ} \mathrm{C}\right)$ & 70 \\
Curing time $(\mathrm{h})$ & 48 \\
\hline
\end{tabular}




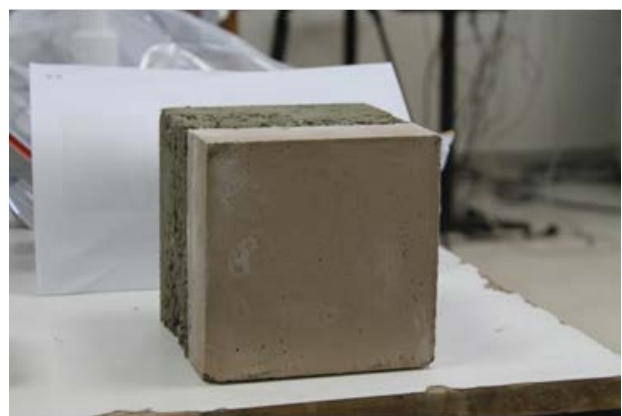

(a)

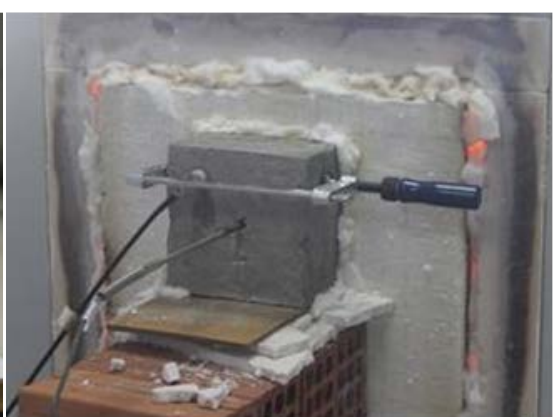

(b)

Figure 3. (a) Specimen before test; (b) Experimental setup during the fire test.

the back surface of the concrete slab was measured with a high performance infrared thermometer (RAYTEK, Raynger MX4). During the test any Acoustic Emission (AE) activity of the specimen was monitored. To capture the $\mathrm{AE}$ signals a piezoelectric $\mathrm{AE}$ transducer with $150 \mathrm{kHz}$ resonant frequency was mounted on the back surface of the concrete. The mineralogical characterization of the fire resistant geopolymer after the fire test was performed by means of X-ray diffractometry (XRD) on a SIEMENS D 5000 diffractometer.

\section{Results and Discussion}

\subsection{Mechanical and Thermophysical Properties}

As it may be observed from Table 3 the geopolymer achieved 9 MPacompressive strength and 1 MPa tensile strength within the period of the first 28 days from its production. The Young Modulus in compression at 28 days wasmeasured equal to $3 \mathrm{GPa}$.The hardness of the geopolymer was measured equal to 90 shore $\mathrm{A}$ rating it as a hard material which is considered good enough for a superficial material. In comparison to other fire resistant materials (Table 3), the metakaolin geopolymer has similar mechanical properties with the Fire Barrier 135 but lower mechanical properties from the Meyco Fireshield 1350.

The thermal conductivity of the metakaolin geopolymer was measured to be $0.21 \mathrm{~W} / \mathrm{m} \cdot \mathrm{K}$ at $300 \mathrm{~K}$ which is substantially lower than the corresponding ones of the commonly used structural building materials, such as concrete blocks $(0.5-0.6 \mathrm{~W} / \mathrm{m} \cdot \mathrm{K})$ and cement or gypsum plasters $(0.2-0.8 \mathrm{~W} / \mathrm{m} \cdot \mathrm{K})$. It is slightly higher from the thermal conductivity value of the Fire Barrier 135 and significantly lower from that of the Meyco Fireshield 1350, as is seen in Table 3. This property is very crucial for the performance of fire resistant materials because it determines the ability of materials to operate as efficient heat flux barriers. In general, for a given heat flux the lowest the thermal conductivity, the highest the established temperature gradient across the fire resistant material. In addition, for given heat flux and predetermined temperature drop inside the fire resistant material the lowest the thermal conductivity, the lowest the thickness of the superficial fire resistant material.

Finally, the density of the metakaolin geopolymer was $1700 \mathrm{~kg} / \mathrm{m}^{3}$ that is similar with the one of the Meyco Fireshield 1350 and substantially higher from the Fire Barrier 135 (Table 3). The metakaolin geopolymer had by far the lowest porosity in relation to Fire Barrier 135 and Meyco Fireshield 1350 (Table 3). For this reason, the geopolymer had the lowest cold water absorption that was measured equal to $8.7 \%$. From this point of view, the geopolymer seems to have an advantage in relation to the commercial fire resistant materials. It is thermally better than the Meyco Fireshield 1350 (substantially lower thermal conductivity value, porosity and water absorption) and has better fire performance than the Fire Barrier 135 which although has slightly lower thermal conductivity value, it has very high porosity as well as water absorption and under real application conditions is expected to undergo deterioration of its thermal properties and become more sensitive in structural damages during a fire incident.

\subsection{Performance to Thermal Loading}

The behavior of the geopolymer during the passive fire protection test is shown in Figure 4, where the attained temperature at the concrete/geopolymer interface, the temperature at the unexposed concrete surface and the furnace temperature simulating the RWS fire load curve are drawn as a function of time. 
Table 3. Physical and mechanical properties of the metakaolin geopolymer and other commercial fire resistant materials with standing the RWS fire load curve.

\begin{tabular}{cccc}
\hline & Fire Barrier 135 [9] & Meyco Fireshield 1350 [9] & Metakaolin Geopolymer \\
\hline Thermal Conductivity at $300 \mathrm{~K}\left(\mathrm{~W} \cdot \mathrm{m}^{-1} \cdot \mathrm{K}^{-1}\right)$ & 0.185 & 0.41 & 0.21 \\
Density $\left(\mathrm{kg} / \mathrm{m}^{3}\right)$ & 1150 & 1800 & 1700 \\
Young Modulus E (MPa) & 4050 & 7900 & 3000 \\
Compressive/Tensile strength (MPa) & $9 / 0.8$ & $15-18 / 1.5$ & $9 / 1$ \\
Porosity (\%) & 66 & 52 & 90 shore A \\
Hardness & 90 shore A & $18 \%$ & $8.7 \%$ \\
\hline
\end{tabular}

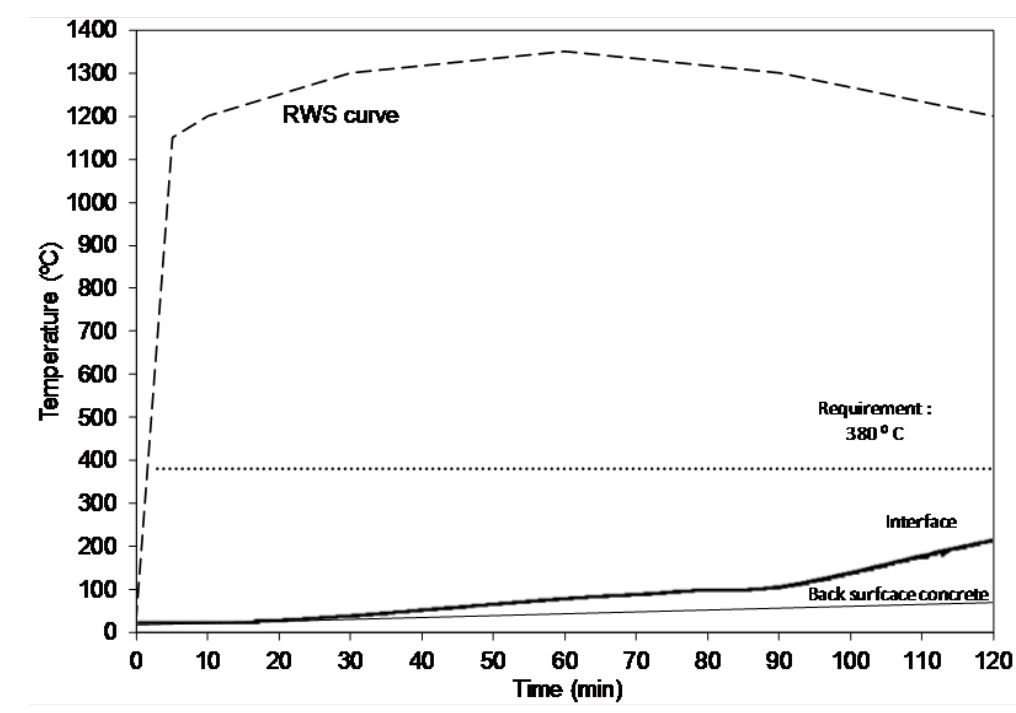

Figure 4. Performance of the metakaolin geopolymer to thermal loading simulating the RWS fire load curve.

As it is observed, the temperature at the geopolymer/concrete interface was lower than $220^{\circ} \mathrm{C}$ during the whole duration of the fire test. This temperature was at least $160^{\circ} \mathrm{C}$ lower than the performance requirements for an efficient fire resistant material set by the E.F.N.A.R.C for a passive fire protection test with the RWS fire loading curve. At the first 25 minutes, where the temperature in the furnace was increased rapidly from the ambient temperature to $1280^{\circ} \mathrm{C}$, the interface temperature was remained at $30^{\circ} \mathrm{C}$ establishing a temperature gradient across the fire resistant geopolymer equal to $25^{\circ} \mathrm{C} / \mathrm{mm}$. Then, the interface temperature started increasing, with a low rate of $1.27^{\circ} \mathrm{C} / \mathrm{min}$ reaching $100^{\circ} \mathrm{C}$ at about 80 minutes of test duration. During this time period the furnace temperature reached the maximum value of the test $\left(=1350^{\circ} \mathrm{C}\right)$, while the temperature at the interface was just $80^{\circ} \mathrm{C}$, establishing a temperature gradient equal to $25.4^{\circ} \mathrm{C} / \mathrm{mm}$ which is attributed to its low thermal conductivity value $(0.21 \mathrm{~W} / \mathrm{m} \cdot \mathrm{k})$. After the 80 minutes of the test, the temperature remained for 6 minutes constant at $100^{\circ} \mathrm{C}$ with a temperature gradient at $23.9^{\circ} \mathrm{C} / \mathrm{mm}$. The temperature plateau at $100^{\circ} \mathrm{C}$ was attributed to the removal of geopolymeric water through an endothermic water evaporation process consuming large amount of the incoming heat due to the large latent heat of water evaporation and keeping the interface temperature more or less constant at around $100^{\circ} \mathrm{C}$. From this point onwards, the temperature at the geopolymer/concrete interface increasedwith an average rate of $3.41^{\circ} \mathrm{C} / \mathrm{min}$ while the furnace temperature decreased to $1200^{\circ} \mathrm{C}$. At the end of the fire test the interface temperature was $216^{\circ} \mathrm{C}$ and the temperature gradient was $19.7^{\circ} \mathrm{C} / \mathrm{mm}$. Finally, the temperature in the back surface of the concrete slab did not exceed $70^{\circ} \mathrm{C}$ during the whole duration of the fire test as is seen in Figure 4, which means that across the concrete slab the temperature was varied in-between $70^{\circ} \mathrm{C}$ and $216^{\circ} \mathrm{C}$, temperatures that do not create damage to the concrete and the structural steel.

As it is seen in Figure 5, the exposed surface of the metakaolin geopolymer after the end of the fire test has 


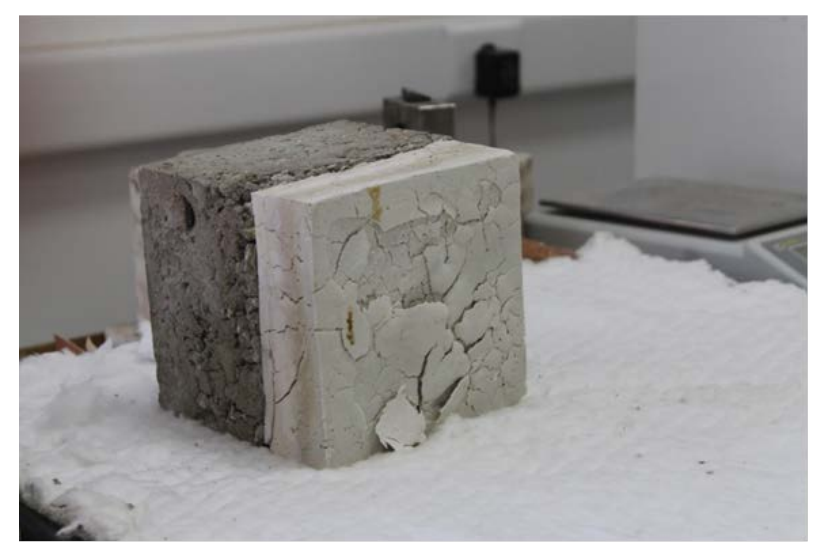

Figure 5. Composite specimen after fire test.

been exfoliated and crackeddue to the sudden loss of geopolymeric water during the whole duration of the fire test. However the geopolymer remained fully bonded to the concrete without losing its structural integrity. The cracking was superficial with maximum width not exceeding $2 \mathrm{~mm}$ and depth lower than $0.5 \mathrm{~mm}$. Smelting phenomena due to exposure at high temperatures were not observed in the geopolymeric material. Its adhesion with the concrete slab assisted by the steel anchors proved to be successful and any serious detachment at the materials interface was not observed. The geopolymer remained on top of the concrete slab without any change in its geometry.

The concrete slab protected by the metakaolin geopolymer did not appear any form of spalling or other mechanical damage and remained as it was initially before the fire test. This was also verified by the acoustic emission monitoring, since no AE signals were detected during the whole test duration. The compressive strength of the concrete slab was estimated after the end of the fire test using a Schmidt hammer (Table 4). The compressive strength remained similar to the one of the concrete before the fire test proving that the concrete did not appear any form of damaging. This means that in case of a fire, the only repair that will be necessary concerns the metakaolin geopolymer coating and not the concrete.

It was clearly observed by a simple comparison of the metakaolin geopolymer specimen before and after the fire test that the physical appearance of the material was changed. Its colour was changed from white to brown and grey indicating that mineralogical transformations took place during the exposure of material at high temperatures. In addition, colour variation across the material thickness was observed, as is shown in Figure 6, indicating that different phase transformations were taken place as a temperature gradient was established across the material during the fire test. Three distinct different thermal zones were observed.

The material in thermal zone Iresembled the initial metakaolin geopolymer (amorphous containing quartz, illite and anatase) as is seen in Figure 7 where the X Rays Diffractograms of the materials in the three thermal zones are shown. This observation indicates that the temperature in thermal zone I was too low to initiate mineralogical transformations. In the thermal zone II, where the temperature was higher, the amorphous aluminosilicate phase had been crystallized and other mineralogical phases appeared, such as leucite and kaliophyllite together with remaining quartz and illite from the silicon dioxide and metakaolin respectively.Finally, the material in the very hot thermal zone III was further recrystallized. It was composed from the refractory mineralogical phases of leucite, kaliophyllite and potassium aluminium oxide which explains the successful behaviour of the material during the thermal test.

The passive fire protection testproved that the material has the ability to put an efficient heat flux barrier protecting the tunnel concrete lining as well as the steel reinforcement from the most severe fire incidents that can happen in underground constructions.

\section{Conclusions}

The fire resistant potassium based geopolymer from metakaolin that was designed and studied in this paper demonstrated, through a series of tests, the following attributes:

1) Its 28 days compressive strength reached the value of 9 MPa with a Young's Modulus in compression 
Table 4. Compressive strength of concrete before and after the fire test.

\begin{tabular}{ccc}
\hline Compressive strength & Before the fire test (ASTM C39) & After the fire test (Schmidt hammer) \\
\hline
\end{tabular}

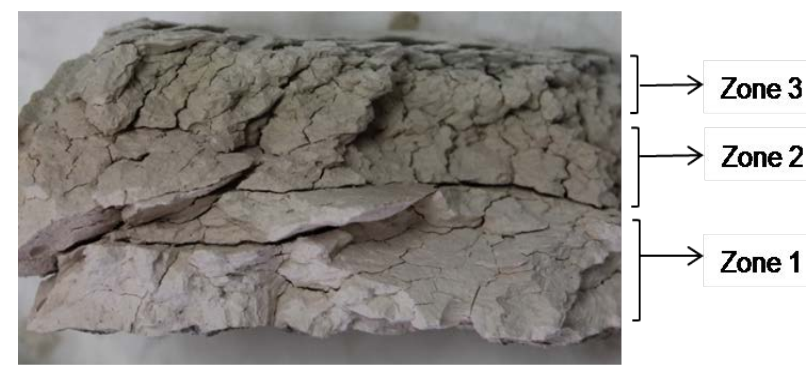

Figure 6. Colour variation across the metakaolin geopolymer after the fire test.

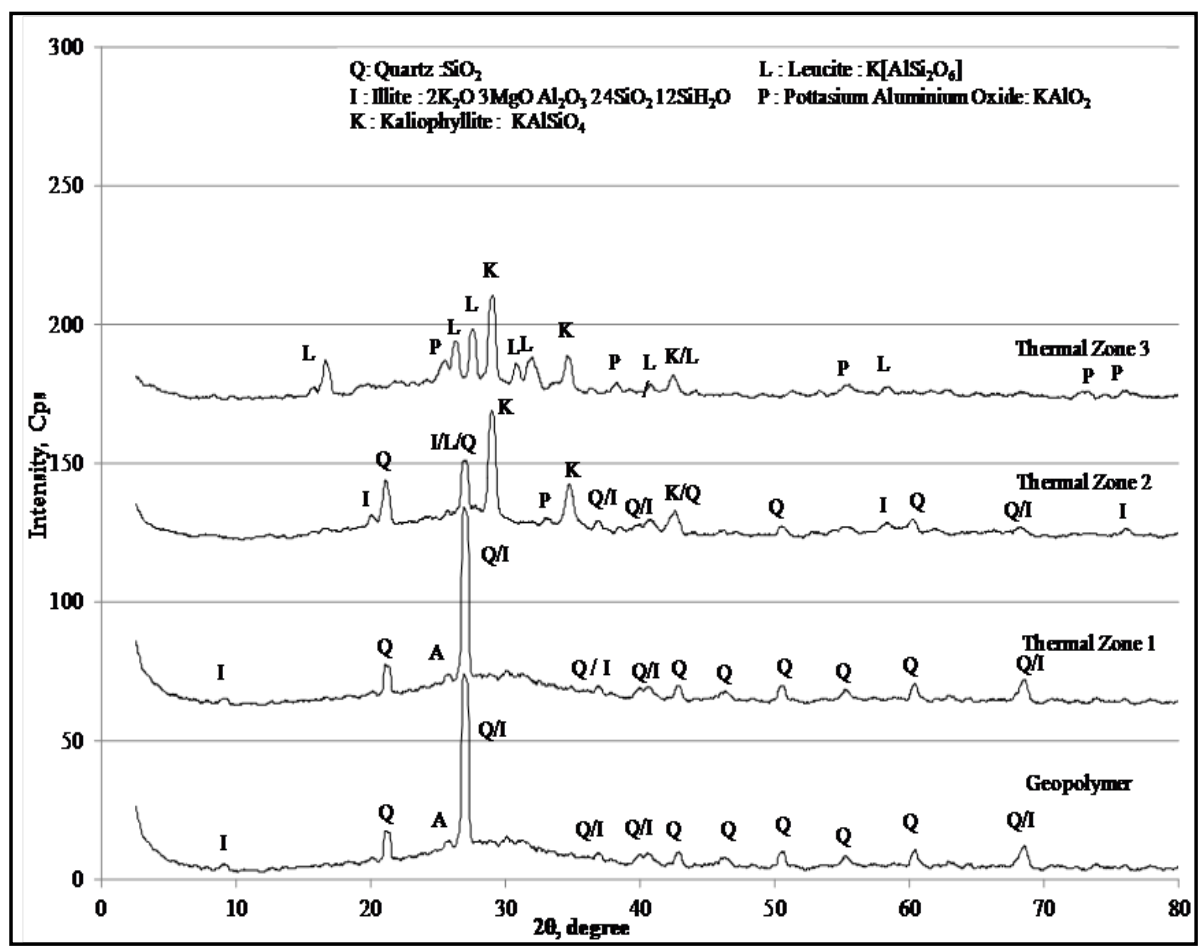

Figure 7. X-ray diffractogram of the initial metakaolin geopolymer as well as the materials in the three different thermal zones after the fire test.

equal to $3 \mathrm{GPa}$, and a tensile strength of $1 \mathrm{MPa}$. The geopolymer hardness was 90 Shore A characterizing this material as a hard one. The mechanical properties of the metakaolin geopolymer are comparable with those of the existing fire proofing materials.

2) The thermal conductivity of the metakaolin geopolymer is $0.21 \mathrm{~W} / \mathrm{m} \cdot \mathrm{K}$ at $300 \mathrm{~K}$ which is substantially lower from the thermal conductivities of the commonly used structural building materials. In comparison to the commercially available fire resistant materials, the thermal conductivity of the metakaolin geopolymer is lower or similar, indicating that it can perform as an insulating superficial coating material setting a thermal barrier in front of the fire sensitive tunnel concrete lining.

3) The geopolymer has a density of $1700 \mathrm{~kg} / \mathrm{m}^{3}$ which is the highest among all the marketable fire resistant materials. The material has the lowest open porosity (29\%) as well water absorption (8.7\%) from all the marketable fire resistant materials. 
4) The behavior of the metakaolin geopolymer during the thermal loading test with the most severe RWS fire load curve was excellent. The maximum temperature at the concrete/geopolymer interface was $216^{\circ} \mathrm{C}$ which is substantially lower from the required temperature set by EFNARC for protection of tunnel concrete linings $\left(\leq 380^{\circ} \mathrm{C}\right)$. The geopolymer appeared exfoliated and cracked at the exposed surface after the test, due to the sudden loss of absorbed water. However, it did not appear any significant structural damage. Furthermore, it remained fully bonded to the concrete specimen, proving the adequacy of the adhesion with the concrete. The steel anchors used in the fire test did not undergo visible deformations or structural disintegration indicating that this anchoring system may be considered for the application of the metakaolin geopolymer on tunnels concrete linings.

5) No concrete spalling was observed during or after the thermal loading test. This was also verified by the absence of any acoustic emission signals during the whole test duration. The compressive strength of the concrete after the fire test remained similar to the one measured before the test.

As a final conclusion, the developed metakaolin geopolymer has been proved, through small scale passive fire protection test, to possess excellent fire resistant properties. It can put an effective heat flux barrier allowing for a successful passive fire protection to the tunnels concrete linings from the most severe fire incidents that can happen in underground constructions.This anticipated behavior should also be verified with large scale as well as pilot tests before any application in practice.

\section{Acknowledgements}

This research has been co-financed by the European Union (European Social Fund-ESF) and Greek national funds through the Operational Program "Education and Lifelong Learning" of the National Strategic Reference Framework (NSRF)-Research Funding Program: Heracleitus II. Investing in knowledge society through the European Social Fund.

\section{References}

[1] Davidson, M.T., Harik I.E. and Davis D.B. (2013) Fire Impact and Passive Fire Protection of Infrastructure: State of the Art. Journal of Performance of Constructed Facilities, 27, 135-143. http://dx.doi.org/10.1061/(ASCE)CF.1943-5509.0000295

[2] N.C.M.A, National Codes and Standards Council of the Concrete and Masonry Industries, 1994. Assessing the Condition and Repair Alternatives of Fire Exposed Concrete and Masonry Members. Fire Protection Planning Report.14.

[3] Davidovits, J. (1999) Chemistry of Geopolymeric Systems, Terminology. Proceedings of the 2nd International Conference on Geopolymer'99, Saint Qunentin, 9-39.

[4] Murri, A.N., Rickard, W.D.A., Bignozzi, M.C. and Van Riessen, A. (2013) High Temperature Behaviour of Ambient Cured Alkali-Activated Materials Based on Ladle Slag. Cement and Concrete Research, 43, 51-61. http://dx.doi.org/10.1016/j.cemconres.2012.09.011

[5] Rickard, W.D.A., Vickers, L. and Van Riessen, A. (2013) Performance of Fibre Reinforced, Low Density Metakaolin Geopolymers under Simulated Fire Conditions. Applied Clay Science, 73, 71-77. http://dx.doi.org/10.1016/j.clay.2012.10.006

[6] Cheng, T.W. and Chiu, J.P. (2003) Fire-Resistant Geopolymer Produced by Granulated Blast Furnace Slag. Minerals Engineering, 16, 205-210. http://dx.doi.org/10.1016/S0892-6875(03)00008-6

[7] EFNARC, European Federation of National Associations Representing Producers and Applicators of Specialist Building Products for Concrete, 2009. Specification and Guidelines for Testing of Passive Fire Protection for Concrete Tunnels Lining.

[8] ISRM (1978) Suggested Methods for Determining Tensile Strength of Rock Materials Part 2: Suggested Method for determining indirect tensile strength by the Brazil Test. International Journal of Rock Mechanics and Mining Sciences, 15, 99-103. http://dx.doi.org/10.1016/0148-9062(78)90003-7

[9] Centre d'etudes des tunnels CETU, 2010. Sprayable mortars for fire protection. http://www.cetu.developpement-durable.gouv.fr/sprayable-mortars-for-firea518.html

[10] (1995) Slag Atlas. 2nd Edition, Verlag Stahleisen GmbH, Düsseldorf. 